\title{
Amphipleuraceae (Bacillariophyceae) do alto da bacia do Ribeirão Cambé, Londrina, Brasil
}

\author{
FRANCISCO STRIQUER SOARES ${ }^{1,4}$, BÁRBARA IDINO BARBOSA KONOPLYA ${ }^{1}$, \\ JOÃO FERNANDO MARQUES DA SILVA² e \\ CÉLIA GUADALUPE TARDELLI DE JESUS ANDRADE ${ }^{3}$
}

(recebido: 09 de dezembro de 2009; aceito: 17 de dezembro de 2010)

\begin{abstract}
Amphipleuraceae (Bacillariophyceae) from Upper Cambé River Basin, Londrina, Brazil). The upper Cambé River basin, located in an urban region of Londrina City, Paraná State, Brazil, receives domestic and industrial residues. The aim of this work was to present the richness of Amphipleuraceae at the upper Cambé River basin with some morphological information of the species. Sampling was sazonal including November 2001, February, May and September 2002. The identified species were: Amphipleura lindheimeri Kützing, Frustulia neomundana Lange-Bertalot \& Rumrich, F. pumilio Rumrich \& Lange-Bertalot, F. undosa Metzeltin \& Lange-Bertalot, F. vulgaris (Thwaites) De Toni, and F. weinholdii Hustedt. Three Frustulia were not identified at species level.
\end{abstract}

Key words - Amphipleura, benthic diatoms, Frustulia, periphyton, urban stream

RESUMO - (Amphipleuraceae (Bacillariophyceae) do alto da bacia do Ribeirão Cambé, Londrina, Brasil). A bacia do Ribeirão Cambé localiza-se na região urbana da cidade de Londrina, Estado do Paraná, Brasil, recebendo esgotos domésticos e industriais. O objetivo deste trabalho foi apresentar a riqueza de Amphipleuraceae no alto da bacia do Ribeirão Cambé juntamente com informações morfológicas das espécies. As coletas foram sazonais, nos meses de novembro de 2001 e fevereiro, maio e setembro de 2002. As espécies identificadas foram: Amphipleura lindheimeri Kützing, Frustulia neomundana Lange-Bertalot \& Rumrich, F. pumilio Rumrich \& Lange-Bertalot, F. undosa Metzeltin \& Lange-Bertalot, F. vulgaris (Thwaites) De Toni e F. weinholdii Hustedt. Três Frustulia não foram identificadas no nível de espécie.

Palavras-chave - Amphipleura, diatomáceas bentônicas, Frustulia, perifíton, rios urbanos

\section{Introdução}

A família Amphipleuraceae é composta pelos gêneros Amphipleura, Frustulia, Frickea e Cistula (Round et al. 1990). Na bacia do Rio Tibagi foram registradas até o presente, espécies dos dois primeiros gêneros, Frustulia rhomboides (Ehr.) De Toni var. rhomboides, por Moreira Filho et al. (1976), e A. lindheimeri Grun. var. lindheimeri, F. rhomboides (Ehr.) De Toni var. rhomboides e F. rhomboides (Ehr.) De Toni var. saxonica, por Moro \& Fürstenberger (1993), ambos na Lagoa Dourada, ambiente lêntico. Moura \& Bittencourt-Oliveira (2004), para ambiente lótico, citaram as espécies $A$. lindheimeri Grun., F. rhomboides (Ehrenb.) De Toni e F. rhomboides var. crassinervia

1. Universidade Estadual de Londrina, Centro de Ciências Biológicas, Departamento de Biologia Animal e Vegetal, Campus Universitário, 86051-990 Londrina, PR, Brasil.

2. Universidade Estadual de Londrina, Centro de Ciências Biológicas, Programa de Pós-Graduação em Ciências Biológicas. Campus Universitário, 86051-990 Londrina, PR, Brasil.

3. Universidade Estadual de Londrina, Centro de Ciências Biológicas, Departamento de Biologia Geral, Campus Universitário, 86051-990 Londrina, PR, Brasil.

4._Autor para correspondência: striquer@uel.br
(Bréb.) Ross. No entanto, próximo à cidade de Londrina só a segunda publicação (Moura \& Bittencourt-Oliveira 2004) registrou $A$. lindheimeri.

Vários estudos têm sido publicados sobre esta família ou sobre o gênero Frustulia (Lange-Bertalot \& Jahn 2000, Wojtal 2003, Lange-Bertalot \& Sterrenburg 2004, Siver \& Baskette 2004), incluindo trabalhos recentes na América do Sul, com material de ecossistemas brasileiros (Metzeltin \& Lange-Bertalot 1998, 2007, Brassac \& Ludwig 2005, Metzeltin et al. 2005). Essas publicações trazem novas propostas taxonômicas, com maior volume de informações sobre morfologia e ecologia, aumentando o número de espécies desta família. Isto indica que novos estudos deste gênero em regiões tropicais podem ampliar o conhecimento da diversidade de espécies.

O presente trabalho tem como objetivo apresentar a riqueza de Amphipleuraceae no alto da bacia do Ribeirão Cambé, juntamente com informações morfológicas das espécies encontradas.

\section{Material e métodos}

A área estudada abrange o alto da bacia do Ribeirão Cambé e três de seus tributários, situados no perímetro 
urbano da cidade de Londrina, PR (pouco mais de 500 mil habitantes), na região Sul do Brasil, com aproximadamente 1.170 ha, representando em torno de $15 \%$ da área total da bacia (figura 1). O Ribeirão Cambé é um afluente do Rio Tibagi e deságua próximo à foz deste, no Rio Paranapanema. Alguns estudos realizados na bacia indicaram, além da introdução de efluentes ricos em nutrientes tais como fosfato, nitrito e nitrato (Camargo \& Martinez 2006), a necessidade de monitoramento de emissões de metais pesados (Yabe \& Oliveira 1998) e a ameaça aos peixes devido a alterações histológicas e fisiológicas constatadas (Winkaler et al. 2001).

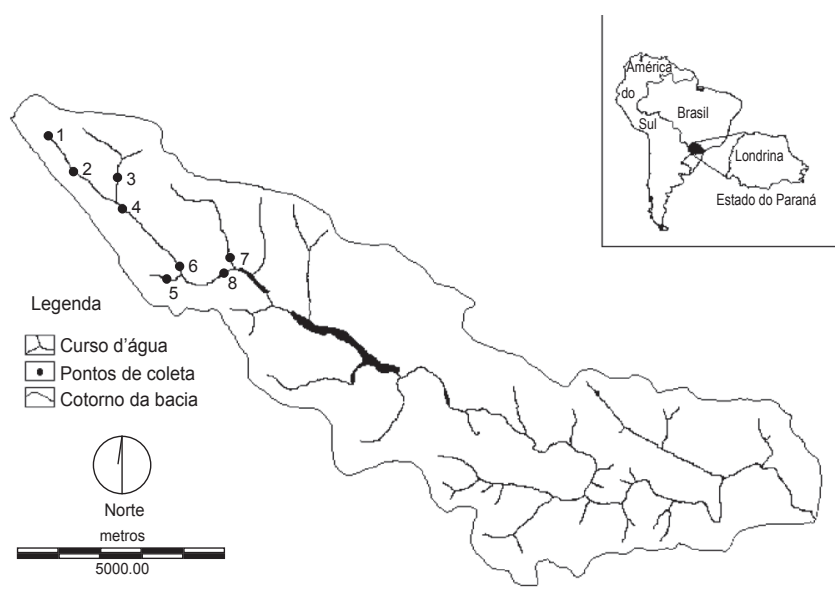

Figura 1. Localização dos oito segmentos amostrados na bacia do Ribeirão Cambé.

Figure 1. Location of the eight river segments sampled along Cambé river.

Para as coletas foram selecionados oito segmentos de rio de $30 \mathrm{~m}$ de comprimento, definidos pela presença da maior diversidade de micro-habitats e acessibilidade aos mesmos, incluindo, sempre que possível, substratos consolidados (epilíton), não consolidados (epipélon e epipsámon) e vegetais (epifíton e epidéndron). As informações sobre os locais de coleta encontram-se na tabela 1 . As coletas foram realizadas nos dias 13, 14 e 21 de novembro de 2001 (primavera, coleta 1), 28 de fevereiro de 2002 (verão, coleta 2), 27 de maio de 2002 (outono, coleta 3) e 6 de setembro de 2002 (inverno, coleta 4).

Para o estudo das diatomáceas foram selecionadas três estações de coleta dentro de cada segmento de rio para cada um dos três tipos de substrato acima citados, conforme presente no segmento. O material foi removido dos substratos consolidados e da vegetação com um pincel e água destilada. Substratos não consolidados foram recolhidos com uma placa de Petri de $5 \mathrm{~cm}$ de diâmetro, introduzida invertida no sedimento e retirada com uma espátula fechando sua abertura. Todo material do mesmo segmento de rio foi reunido em um único frasco e fixado com $50 \%$ de solução Transeau. As amostras foram depositadas na Coleção de Algas do Herbário da Universidade Estadual de Londrina (FUEL-Algae) e estão identificados na tabela 2.

No laboratório, para a limpeza das frústulas, foram feitas subamostras de $2 \mathrm{~mL}$ das amostras, depois de homogeneizadas, e submetidas ao tratamento com peróxido de hidrogênio e ácido clorídrico (Dell’Uomo 2004). A montagem das lâminas permanentes foi executada com Naphrax e três lâminas de cada segmento de rio foram examinadas ao Microscópio Zeiss, modelo Axioskop, com uma câmara fotográfica digital acoplada. As lâminas permanentes foram depositadas no laminário da Coleção de Algas do Herbário da Universidade Estadual de Londrina e estão identificadas na tabela 2.

Parte da amostra limpa e homogeneizada foi depositada sobre uma lamínula $(0,5 \mathrm{~cm} \times 0,5 \mathrm{~cm})$ e seca em estufa à $70{ }^{\circ} \mathrm{C}$. A seguir, foram fixadas em suportes de alumínio, os quais receberam coberturas com ouro. Observações, medidas e imagens em MEV foram feitas em equipamento FEI, modelo Quanta 200.

As identificações dos táxons basearam-se em Round et al. (1990), Metzeltin \& Lange-Bertalot (1998), Krammer \& Lange-Bertalot (1999, 2000) e Metzeltin et al. (2005).

Tabela 1. Identificação do segmento do curso de água, posição geográfica e tipo de substrato presente nos segmentos de rio.

Table 1. River segment identification, stream name, geographic coordinates and substratum.

\begin{tabular}{|c|c|c|}
\hline Segmento de rio & Localização & Tipo do substrato \\
\hline 1 & Ribeirão Cambé, $23^{\circ} 17^{\prime} 15^{\prime \prime} \mathrm{S}$; 5113'58” W & Vegetação, lodo e rocha \\
\hline 2 & Ribeirão Cambé, $23^{\circ} 17^{\prime} 49^{\prime \prime} \mathrm{S} ; 51^{\circ} 13^{\prime} 58^{\prime \prime} \mathrm{W}$ & Vegetação, lodo e rocha \\
\hline 3 & Córrego Cacique, $23^{\circ} 17^{\prime} 51^{\prime \prime} \mathrm{S} ; 51^{\circ} 13^{\prime} 01^{\prime \prime} \mathrm{W}$ & Vegetação e lodo \\
\hline 4 & Ribeirão Cambé, $23^{\circ} 18^{\prime} 45^{\prime \prime} \mathrm{S} ; 51^{\circ} 13^{\prime} 05^{\prime \prime} \mathrm{W}$ & Vegetação, lodo e rocha \\
\hline 5 & Córrego da Mata, $23^{\circ} 19^{\prime} 05^{\prime \prime} \mathrm{S} ; 51^{\circ} 12^{\prime} 18^{\prime \prime} \mathrm{W}$ & Vegetação e rocha \\
\hline 6 & Ribeirão Cambé, $23^{\circ} 18^{\prime} 45^{\prime \prime} \mathrm{S} ; 51^{\circ} 12^{\prime} 17^{\prime \prime} \mathrm{W}$ & Vegetação e rocha \\
\hline 7 & Córrego Baroré, $23^{\circ} 18^{\prime} 51^{\prime \prime} \mathrm{S} ; 51^{\circ} 11^{\prime} 27^{\prime \prime} \mathrm{W}$ & Vegetação e rocha \\
\hline 8 & Ribeirão Cambé, $23^{\circ} 19^{\prime} 11^{\prime \prime} \mathrm{S} ; 51^{\circ} 11^{\prime} 47^{\prime \prime} \mathrm{W}$ & Vegetação, lodo e rocha \\
\hline
\end{tabular}


Tabela 2. Identificação das amostras na Coleção de Algas (FUEL-Algae) do Herbário da Universidade Estadual de Londrina (FUEL) e das lâminas analisadas por segmento de rio.

Table 2. Samples identification in the Algae Collection (FUEL-Algae) at Herbário da Universidade Estadual de Londrina (FUEL), and analised slides of each river segment.

\begin{tabular}{|c|c|c|c|c|c|c|c|c|}
\hline \multirow{2}{*}{$\begin{array}{l}\text { Segmento } \\
\text { de rio }\end{array}$} & \multicolumn{2}{|c|}{13,14 e $21 / 11 / 2001$} & \multicolumn{2}{|c|}{$28 / 02 / 2002$} & \multicolumn{2}{|c|}{$27 / 05 / 2002$} & \multicolumn{2}{|c|}{$06 / 09 / 2002$} \\
\hline & Amostras & Lâminas & Amostras & Lâminas & Amostras & Lâminas & Amostras & Lâminas \\
\hline 1 & 723 & $7, \quad 8, \quad 9$ & 750 & $189,190,191$ & 775 & $404,405,406$ & 800 & $576,577,578$ \\
\hline 2 & 726 & $30,31,32$ & 753 & $219,220,221$ & 778 & $421,422,423$ & 803 & $586,587,588$ \\
\hline 3 & 730 & $48, \quad 19,50$ & 757 & $252,253,254$ & 782 & $438,439,440$ & 806 & $598,599,600$ \\
\hline 4 & 733 & $74,75,76$ & 760 & $282,283,284$ & 785 & $469,470,471$ & 809 & $610,611,612$ \\
\hline 5 & 737 & $99,100,101$ & 763 & $304,305,306$ & 788 & $492,493,494$ & 812 & $615,616,617$ \\
\hline 6 & 740 & $123,124,125$ & 766 & $325,326,327$ & 791 & $516,517,518$ & 815 & $619,620,626$ \\
\hline 7 & 743 & $141,142,143$ & 769 & 353,354 & 794 & $541,542,543$ & 818 & $624,625,626$ \\
\hline 8 & 746 & $164,165,166$ & 771 & $380,381,382$ & 797 & $562,563,564$ & 820 & $629,630,631$ \\
\hline
\end{tabular}

\section{Resultados e discussão}

\section{Amphipleura lindheimeri Grunow 1862}

Figuras 2-4

Valvas rômbico-lanceolados ou fusiformes (figuras 2 e 3); ápices arredondados. Helictoglossa curta (figura 4), com bordas abertas, mas que vão se aproximando em direção à rafe, à semelhança dos contornos de uma gota. Rafe curta e reta, cada ramo variou de 22,1-30,0 $\mu \mathrm{m}$ $(n=15)$ de comprimento, representando $16,6-20,9 \%$ do comprimento total da valva. Costela robusta e única, que se abre nas extremidades, à semelhança de um diapasão, para envolver a rafe; as extremidades distais deste diapasão se abrem levemente, envolvendo parcialmente a helictoglossa (figura 4). Estrias longitudinais paralelas e onduladas, variando de $31-33 / 10 \mu \mathrm{m}$; transapicais paralelas entre si, tornando-se radiais somente junto à helictoglossa. Aréolas arredondadas, com $32 / 10 \mu \mathrm{m}$. O comprimento e a largura $(n=30)$ variaram de $122,8-199,8 \mu \mathrm{m} \times 15,5-24,8 \mu \mathrm{m}$, médias de $143,7 \mu \mathrm{m} \times 20,9 \mu \mathrm{m}$.

Até o presente somente $A$. lindheimeri foi citada neste gênero em trabalhos na bacia do Rio Tibagi (Rodrigues 1991, Moro \& Fürstenberger 1993, Moura $\&$ Bittencourt-Oliveira 2004). De acordo com Patrick \& Reimer (1966), esta espécie difere de A. pellucida por ter "(1) o comprimento variável dos braços da rafe e (2) a costela de sílica que conecta as duas partes da rafe é geralmente mais larga no centro que nas extremidades". O engrossamento central da costela não foi verificado nos exemplares estudados mesmo em MEV. No entanto a forma geral, o comprimento e a largura da valva e o comprimento e proporção da rafe diferem dos apresentados para A. pellucida pelos autores acima.

Frustulia neomundana Lange-Bertalot \& Rumrich 2000 Figuras 5-11

Valvas elíptico-alongadas a linear, com ápices rostrados a levemente capitados (figuras 5-7). Nódulo central longitudinalmente curto, mas engrossado transversalmente; 0,54-0,58 $\mu \mathrm{m}$ em largura (figura 8). Helictoglossa alongada e fechada, de forma linear (figura 9). Rafe reta, com extremidades internas e externas simples, tanto proximais como distais; extremidades proximais externas curvadas para o mesmo lado, até próximo da primeira aréola da estria longitudinal em sua continuação (figura 10); este lado coincide com o interno em que as extremidades proximais das costelas quase se tocam. Extremidades proximais das costelas assimétricas (figura 8), não se fundindo com o nódulo central e as distais terminam distantes da helictoglossa (figura 9). Área central assimétrica, com duas estrias transapicais que avançam entre as extremidades curvadas da rafe, com uma e duas aréolas, formando um triângulo (figura 10). Área axial reta. Estrias longitudinais onduladas, com 34-40/10 $\mu \mathrm{m}$. Estrias transapicais paralelas ou sigmóides e às vezes incompletas na região central, convergentes na região subapical e radiadas em torno da helictoglossa, tendo algumas estrias menores entre as inteiras. Aréolas variando de $36-40 / 10 \mu \mathrm{m}$. O comprimento e a largura $(n=30)$ variaram de $30,6-45,1 \mu \mathrm{m} \times 6,3-9,2 \mu \mathrm{m}$, média de $37,5 \mu \mathrm{m} \times 8,2 \mu \mathrm{m}$.

A assimetria da área central interna da valva torna F. neomundana distinta das outras espécies, mesmo ao microscópio óptico (MO). Além disso, as extremidades 
distais terminam distantes da helictoglossa e as proximais não se fundem ao nódulo central, incluindo os que quase se tocam, onde o engrossamento lateral é do lado oposto ao do nódulo central.

Foi observado no MEV um espécime com as extremidades proximais das costelas de um mesmo lado contínuas na área central e sem engrossamento lateral (figura 11).

Frustulia pumilio Rumrich \& Lange-Bertalot 2000 Figuras 12-15

Valvas lanceoladas, com ápices arredondados (figuras 12-14). Helictoglossa linear, com bordas abertas em forma de "U" (figura 15), abertura maior do que em F. undosa. Rafe reta, com extremidades internas simples; extremidades externas não foram visualizadas. Costelas retas, grossas e paralelas entre si; com extremidades proximais terminando distantes do nódulo central; extremidades distais envolvendo a helictoglossa, mas não se fundindo a esta. Área central interna com extremidades proximais das costelas distantes entre si. Estrias longitudinais levemente onduladas, com 36-37/10 $\mu \mathrm{m}$. Estrias transapicais paralelas entre si, com 39-40 aréolas em $10 \mu \mathrm{m}$. O comprimento e a largura $(n=7)$ variaram de 19,6-32,2 $\mu \mathrm{m} \times 4,8-6,6 \mu \mathrm{m}$, média de $24,5 \mu \mathrm{m} \times 5,49 \mu \mathrm{m}$.

Estrias inconspícuas ao MO, mas contadas ao MEV a partir da superfície interna da valva, uma vez que não obtivemos superfície valvar externa ao MEV. A melhor característica para identificar esta espécie ao MO são as costelas retas e paralelas, com suas extremidades, tanto as distais como as proximais, terminando junto à helictoglossa e ao nódulo central respectivamente; estes aparecendo mais densos nas frústulas.

As variações morfológicas encontradas nesta espécie ao MEV foram valvas com um a margem estrangulada e a outra normal (figura 13), ou seja, com um lado côncavo e o outro convexo.

\section{Frustulia undosa Metzeltin \& Lange-Bertalot 1998} Figuras 16-23

Valvas lanceoladas a rômbico-lanceoladas com margens trionduladas (figuras 16-20); ápices subrostrados a rostrados. Nódulo central alongado e estreito (figura 21). Helictoglossa linear, com as bordas levemente entreabertas, formando um arco (figura 22). Rafe levemente curvada, com as extremidades internas simples e externas em forma de " $T$ " (figura 23). Costelas robustas, levemente curvadas, com extremidades proximais levemente engrossadas, dando a aparência de um oito à área central ao MO. Helictoglossa não totalmente envolvida pelas extremidades das costelas. Estrias longitudinais paralelas e onduladas, com $32 / 10 \mu \mathrm{m}$. Estrias transapicais paralelas entre si na região mediana da valva e levemente convergentes na região subapical, com 28 aréolas em $10 \mu \mathrm{m}$. O comprimento e a largura $(n=60)$ variaram de $27,6-72,9 \mu \mathrm{m} \times 7,8$ $17,1 \mu \mathrm{m}$, média de $53,8 \mu \mathrm{m} \times 12,7 \mu \mathrm{m}$.

As variações morfológicas destes espécimes são semelhantes às de $F$. undosa descrita por Metzeltin \& Lange-Bertalot (1998). As valvas maiores apresentaram a ondulação da margem menos pronunciada, tornando sua forma mais rombóide; enquanto as menores, com ondulação mais pronunciada, foram mais lanceoladas (Metzeltin \& Lange-Bertalot 1998, prancha 116:14-17 e 117:1-7). Frustulia crassinervia, descrita por Moura \& Bittencourt-Oliveira (2004) e Brassac \& Ludwig (2005) para o Estado do Paraná, tem os ápices rostrados e subcapitados, diferindo das descritas neste trabalho que foram subrostrados a rostrados.

\section{Frustulia vulgaris (Thwaites) De Toni 1848}

Figuras 24-28

Valvas lanceoladas (figuras 24-25); com margens longitudinais onduladas, quase irreconhecíveis ao $\mathrm{MO}$; ápices arredondados a levemente rostrados. Nódulo central alongado (figura 26). Helictoglossa com forma linear (figura 27), levemente aberta. Rafe curvada para uma das laterais da valva, com extremidades externas arredondadas (figura 28) e as internas simples. Costelas estreitas e arqueadas; extremidades proximais distantes entre si, não se fundindo com o nódulo central, bem como as distais em relação à helictoglossa; extremidades distais e proximais se abrem lateralmente como canalizando algum fluxo. Área central interna ampla. Área central externa elíptica (figura 28). Área axial aberta lateralmente, sendo mais larga na região mediana de cada metade da valva. Estrias longitudinais onduladas, com 32-34/10 $\mu \mathrm{m}$. Estrias transapicais radiadas na região central, tornando-se convergentes na região subapical e radiadas junto à helictoglossa, com 34-36 aréolas/10 $\mu \mathrm{m}$. Comprimento e largura $(n=30)$ variaram de 39,3$76,1 \mu \mathrm{m} \times 7,8-10,9 \mu \mathrm{m}$, médias de 46,9 $\mu \mathrm{m} \times 9,0 \mu \mathrm{m}$.

Frustulia vulgaris apresentaram as extremidades proximais das costelas terminando distantes entre si, neste caso, formando uma área central bastante larga, em forma elíptica; as extremidades distais das costelas terminam junto da helictoglossa. As descrições de $F$. vulgaris, com fotografias ao MEV, mostram as aréolas que contornam a área central, menores (Wojtal 2003, figura 

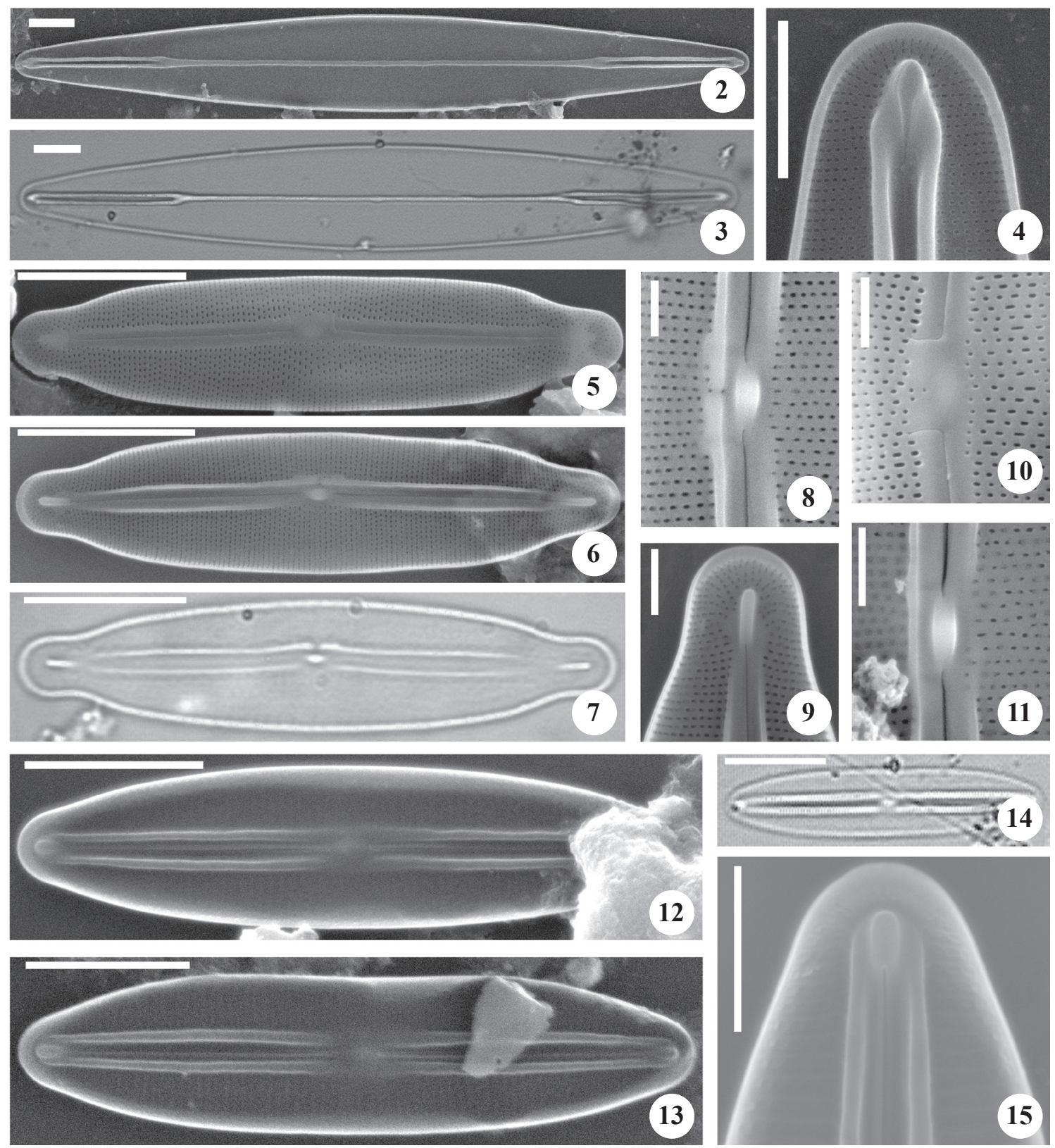

Figuras 2-15. 2-4. Amphipleura lindheimeri. 2. Micrografia de microscópio eletrônico de varredura (MEV) em vista valvar interna. 3. Micrografia ótica (MO) da valva. 4. MEV em vista interna da extremidade valvar, incluindo a helictoglossa. 5-11. Frustulia neomundana. 5. Vista valvar externa (MEV). 6. Vista valvar interna (MEV). 7. Vista valvar (MO). 8. Vista da área central interna (MEV). 9. Vista interna da extremidade valvar, incluindo a helictoglossa (MEV). 10. Vista externa da área central da valva (MEV). 11. Vista interna da área central (MEV), tendo as extremidades proximais de uma das costelas contínuas. 12-15. Frustulia pumilio. 12. Vista valvar interna (MEV). 13. Vista valvar interna (MEV), mostrando assimetria. 14. Vista valvar (MO). 15. Vista interna da extremidade valvar com a helictoglossa (MEV). Barra $=1 \mu \mathrm{m}(15), 2 \mu \mathrm{m}(8,9,10,11), 5 \mu \mathrm{m}$ $(4,12,13,14), 10 \mu \mathrm{m}(2,3,5,6,7)$.

Figures 2-15. 2-4. Amphipleura lindheimeri. 2. Internal valvar view of Scanning Electron Micrograph (SEM). 3. Valvar optical micrograph (OM). 4. Internal view of valvar end (SEM) with the helictoglossae. 5-11. Frustulia neomundana. 5. External valvar view (SEM). 6. Internal valvar view (SEM). 7. Valvar view (OM). 8. Internal view of central area (SEM). 9. Internal view of valvar end (SEM) with the helictoglossae. 10. External view of valvar central area (SEM). 11. Internal view of central area (SEM) with one rib proximal ends continuous. 12-15. Frustulia pumilio. 12. Internal valvar view (SEM). 13. Internal valvar view (SEM), with asymmetric sides. 14. Valvar view (OM). 15. Internal view of valvar end with the helictoglossae (SEM). $\operatorname{Bar}=1 \mu \mathrm{m}(15), 2 \mu \mathrm{m}(8,9,10,11), 5 \mu \mathrm{m}(4,12,13,14), 10 \mu \mathrm{m}(2,3,5,6,7)$. 
2c) quando comparadas com a figura 28 deste estudo, e as extremidades externas da rafe em forma de "Y" (Cox 1999, Wojtal 2003). Entretanto, Cox (1999), estudando a morfogênese da valva desta espécie, verificou que o padrão aqui encontrado é uma fase intermediária de sua formação. No entanto, a consistência das frústulas não parecia estar em um estágio intermediário de formação, com deposição incompleta de sílica, como nas figuras de Cox (1999, figuras 19-24 e 27-29). Encontramos outros dois indivíduos, em MEV, onde as extremidades da rafe tinham a forma de delta. Novos estudos são necessários para confirmar se estas variações são naturais e os indivíduos estavam em desenvolvimento.

\section{Frustulia weinholdii Hustedt 1937}

Figuras 29-34

Valvas linear-lanceoladas, com ápices arredondados a capitados (figura 29-31). Nódulo central curto e largo (figura 32). Helictoglossa de forma linear fechada (figura 33). Rafe reta, com extremidades distais internas e externas e proximais internas simples e proximais externas curvando-se para o mesmo lado na área central (figura 34). Costelas curtas, levemente curvadas, distanciando-se na região mediana de cada braço, com as extremidades proximais e distais terminando distante do nódulo central e da helictoglossa respectivamente. Área central assimétrica, com as extremidades das estrias transapicais de um dos lados avançando entre as extremidades curvadas da rafe em uma a três aréolas. Estrias longitudinais onduladas, com 34-37/10 $\mu \mathrm{m}$. Estrias transapicais paralelas, tornando-se radiadas ou sigmóides nos ápices valvares, devido à presença de pequenas estrias nas margens, com 34-40 aréolas em $10 \mu \mathrm{m}$. Comprimento e largura $(n=23)$ variaram de 22,8 $46,1 \mu \mathrm{m} \times 6,8-9,6 \mu \mathrm{m}$, médias de 34,0 $\mu \mathrm{m} \times 8,3 \mu \mathrm{m}$.

Esta espécie difere das outras do gênero por ter as extremidades proximais e distais das costelas terminando proporcionalmente mais distantes do nódulo central e da helictoglossa, deixando-as totalmente isoladas destas estruturas, formando uma área central maior que nas outras espécies. É bem perceptível ao MO a disposição dos ramos das costelas assemelhando-se aos símbolos gráficos de abrir e fechar parênteses justapostos.

Variações morfológicas foram observadas em pelo menos um organismo das espécies $F$. neomundana, $F$. pumilio, como citado acima, e $F$ weinholdii. Esta última espécie teve estrangulamentos das valvas, em ambos os lados, em seu eixo longitudinal, próximo à região central (figura 29). Anormalidades na forma da valva podem ser atribuídas à presença de metais pesados
(Stevenson \& Pan 1999), como verificado por Gómez \& Licursi (2003) em Pinnularia gibba Ehrenberg e outras espécies de Pennales por Morin et al (2008a). Yabe \& Oliveira (1998), estudando a concentração de metais pesados dissolvidos nas águas do Ribeirão Cambé, encontraram presença frequente de $\mathrm{Pb}, \mathrm{Ni}, \mathrm{Cd}, \mathrm{Cr}$ e $\mathrm{Cu}$. Tais visualizações foram encontradas frequentemente mesmo ao MO, mas não contadas ou mesmo registradas. Entretanto, estes registros podem ser úteis para fornecer monitoramento da poluição das águas por metais pesados (Morin et al. 2008b), justificando estudos específicos sobre o assunto.

\section{Frustulia sp.1}

Figuras 35-41

Valvas lineares a lanceoladas, com ápices rostrados (figuras 35-37). Nódulo central alongado (figura 38). Helictoglossa em forma linear, levemente entreaberta (figura 39), similar à de F. undosa. Rafe levemente curvada, com extremidades internas simples e externas em forma de "T" (figuras 38-41). Costelas robustas, levemente curvas, com extremidades proximais levemente engrossadas, dando à área central interna a aparência do número oito, quando visualizada ao MO. Helictoglossa envolvida parcialmente pelas extremidades distais das costelas. Área central curva para um dos lados. Área axial reta. Estrias longitudinais levemente onduladas e paralelas, com $28-30 / 10 \mu \mathrm{m}$. Estrias transapicais paralelas na região mediana e radiada nos ápices, com 31-32 aréolas $/ 10 \mu \mathrm{m}$. Comprimento e largura $(n=24)$ variaram de 30,6-42,9 $\mu \mathrm{m} \times 8,4-11,2 \mu \mathrm{m}$, com média de $36,6 \mu \mathrm{m} \times 10,2 \mu \mathrm{m}$.

Frustulia sp.1 é semelhante a F. rhomboides var. saxonica (Krammer \& Lange-Bertalot 1999, figuras 95:6-7; Patrick \& Reimer 1966), a F. saxonica (Siver \& Baskette 2004, figuras 4-6) e ao espécime não identificado de Metzeltin et al. (2005, prancha 109:13). Comparando com $F$. rhomboides var. saxonica, esta população tem as valvas maiores e com menos estrias. Em relação a $F$. saxonica, revelou uma variação menor no comprimento e largura $(30,6-42,9 \mu \mathrm{m} \times 8,4-11,2 \mu \mathrm{m})$ que nas amostras dos autores citados (35-75 $\mu \mathrm{m} \times 9,1-18,2 \mu \mathrm{m})$. O ápice valvar de Siver \& Baskette (2004, figura 62) apresenta as estrias longitudinais paralelas, mas abrindo-se próximo à extremidade da rafe, com uma área elíptica livre de aréolas e a extremidade da rafe em forma de "T", e uma estria com apenas uma aréola alongada no ápice. Na figura 41 pode ser observada a primeira estria longitudinal, justaposta à rafe, continuando reta mesmo após a rafe, criando uma área retangular sem estrias no 

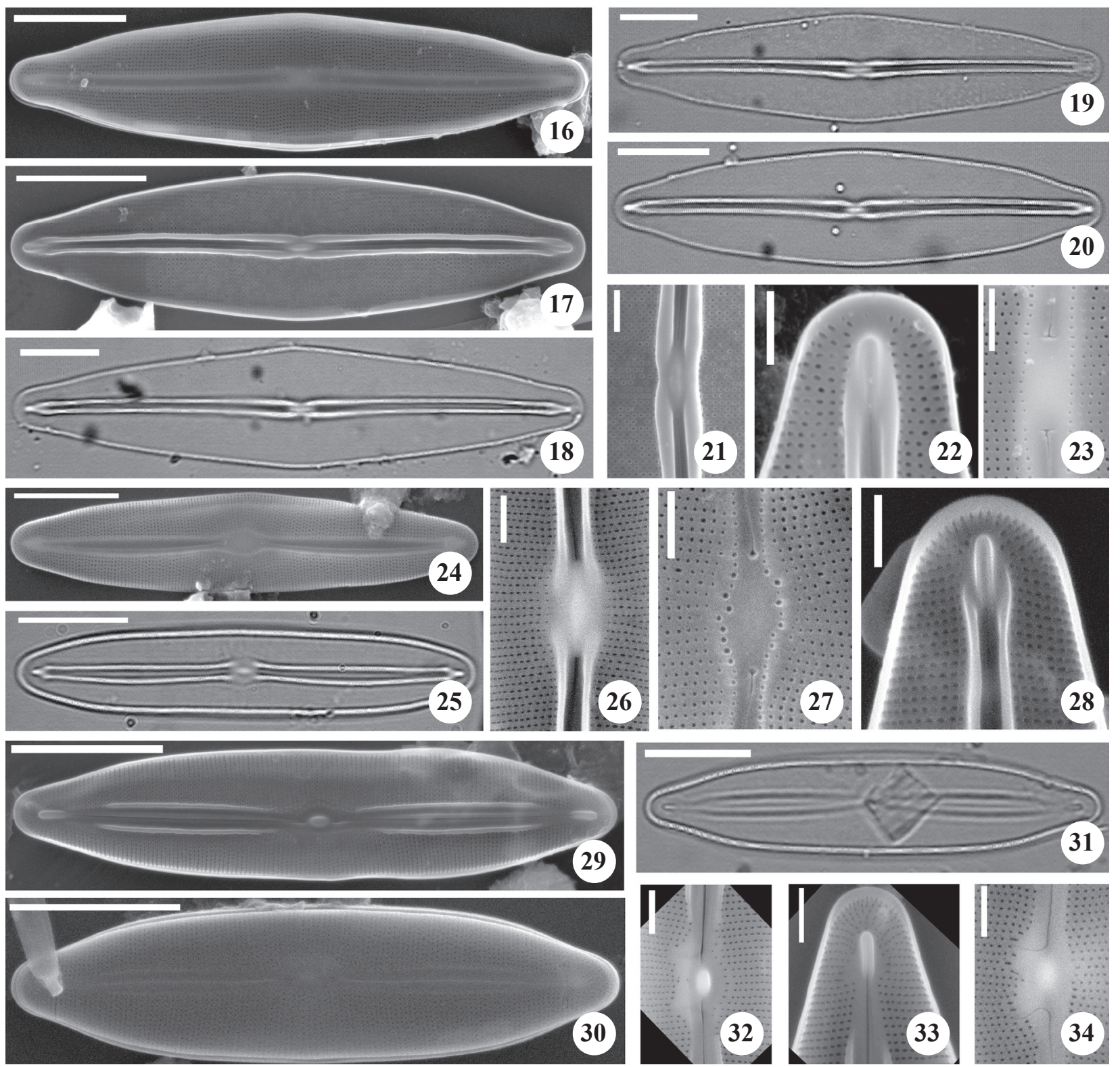

Figuras 16-34. 16-23. Frustulia undosa. 16. Vista valvar externa (MEV). 17. Vista valvar interna (MEV). 18-20. Vista valvar (MO). 21. Vista interna da área central da valva (MEV). 22. Vista interna da extremidade valvar com a helictoglossa (MEV). 23. Vista externa da área central da valva (MEV). 24-28. Frustulia vulgaris. 24. Vista valvar externa (MEV). 25. Vista valvar (MO). 26. Vista interna da área central (MEV). 27. Vista externa da área central (MEV). 28. Vista da extremidade valvar interna com a helictoglossa (MEV). 29-34. Frustulia weinholdii. 29. Vista valvar interna (MEV). 30. Vista valvar externa (MEV). 31. Vista valvar (MO). 32. Vista interna da área central (MEV) com o nódulo central. 33. Vista interna da extremidade apical da valva (MEV) com a helictoglossa. 34. Vista externa da área central (MEV). Barra $=1 \mu \mathrm{m}(22,26,27,28,32,33,34), 2 \mu \mathrm{m}$ $(21,23), 10 \mu \mathrm{m}(16,17,18,19,20,24,25,29,30,31)$.

Figures 16-34. 16-23. Frustulia undosa. 16. Internal valvar view (SEM). 17. Internal valvar view (SEM). 18-20. Valvar view (OM). 21. Internal view of valvar central area (SEM). 22. Internal view of valvar end with the helictoglossae (SEM). 23. External view of valvar central area (SEM). 24-28. Frustulia vulgaris. 24. External valvar view (SEM). 25. Valvar view (OM). 26. Internal view of central area (SEM). 27. External view of central area (SEM). 28. Internal view of valvar end (SEM) with the helictoflossae. 29-34. Frustulia weinholdii. 29. Internal valvar view (SEM). 30. External valvar view (SEM). 31. Valvar view (OM). 32. Internal view of central area (SEM) with the central nodulum. 33. Internal view of valvar end (SEM) with the helictoglossae. 34. External view of central area (SEM). Bar $=1 \mu \mathrm{m}(22,26,27,28,32,33,34), 2 \mu \mathrm{m}(21,23), 10 \mu \mathrm{m}(16$, $17,18,19,20,24,25,29,30,31)$. 
ápice; duas estrias alongadas retas fecham a área apical retangular. O espécime de Metzeltin et al. (2005) é muito semelhante aos observados neste estudo.

\section{Frustulia sp.2}

Figuras 42-48

Valvas lineares a lanceoladas, com ápices capitados (figuras 42-44). Nódulo central alongado (figura 45). Helictoglossa linear, com margens abertas, quase formando um arco, com uma das laterais mais longa que a outra (figura 46). Rafe reta, com as extremidades internas simples e externas em forma de "T" (figuras 47-48). Costelas robustas, retas e paralelas entre si, com extremidades proximais levemente engrossadas. Área central interna tem a aparência de um oito ao $\mathrm{MO}$, devido ao engrossamento das extremidades proximais das costelas. Helictoglossa envolvida parcialmente pelas extremidades distais das costelas. Estrias longitudinais levemente onduladas, com 34-38/10 $\mu \mathrm{m}$. Estrias transapicais paralelas, tornando-se radiadas junto à helictoglossa, com 35-36 aréolas $/ 10 \mu \mathrm{m}$. O comprimento e a largura $(n=60)$ variaram de $30,6-53,5 \mu \mathrm{m} \times 7,8-18,4 \mu \mathrm{m}$, com médias de 41,4 $\mu \mathrm{m} \times 10,9 \mu \mathrm{m}$.

Os organismos aqui identificados como Frustulia sp.2 apresentaram um grupo de características que os aproximam de $F$. rhomboides var. capitata (Patrick \& Reimer 1966, prancha 21:8), mas com menos estrias, tanto longitudinais como transapicais, e com margem valvar sem as três ondulações. A população encontrada no Ribeirão Cambé está mais próxima do apresentado por Metzeltin et al. (2005, prancha 109:11). Nosso material ainda difere de F. crassinervia (Costa 1995), que apresenta ápices significativamente menos capitados e valva mais estreita.

\section{Frustulia sp.3}

Figuras 49-52

Valvas rombóides com ápices arredondados (figura 49). Rafe reta, com extremidades externas, tanto proximais como distais, em forma de "T" (figuras $50 \mathrm{e}$ 51). Costelas retas, paralelas entre si, as extremidades proximais se fundem, tornando-se mais grossas, formando um " $\mathrm{H}$ " com as laterais convexas; as extremidades distais se fundem com a helictoglossa. Estrias longitudinais paralelas, levemente onduladas, com 19/10 $\mu \mathrm{m}$. Estrias transapicais paralelas na região mediana, tornando-se levemente convergentes na região subapical e radiadas em torno da helictoglossa (figuras 50 e 52); com 22 aréolas $/ 10 \mu \mathrm{m}$. Comprimento: 130,3 $\mu \mathrm{m}$. Largura: $25,1 \mu \mathrm{m}$.
Foi registrado apenas um exemplar desta espécie no segmento de rio 7, na primavera (figura 52), tornando difícil fazer uma caracterização mais completa. A morfologia apresentou grande similaridade com $F$. krammeri descrita por Silver \& Baskette (2004, figura 22), mas não apresentou as extremidades proximais das costelas junto ao nódulo central formando um oito, a densidade de estrias e aréolas é menor e é mais larga. Também apresentou semelhanças com $F$. altimontana registrada por de Metzeltin \& Lange-Bertalot (1998, prancha 113:1), mas esta foi encontrada em região andina, de altitude.

Distribuição - A figura 53 apresenta um esquema dos rios com a posição dos segmentos de coleta e a presença ou ausência das espécies estudadas. A que apareceu em maior número de segmentos foi $F$. vulgaris, em 25 dos 32 amostrados. Este táxon foi encontrado em sete segmentos na primavera e em sete no outono, em seis no verão e em cinco no inverno; esteve sempre presente nos segmentos dois, quatro, sete e oito. Segundo Torrisi \& Dell'Uomo (2001), é um táxon cosmopolita e a encontraram mais frequentemente na região ritral, próximo das nascentes, do que na região potamal de rios dos Apeninos Centrais, Itália. Estes autores colocaram esta espécie no grupo característico de águas de boa qualidade.

A segunda foi $F$. neomundana, em 23 segmentos, sendo seis em cada uma das estações do ano primavera, outono e inverno e em cinco no verão; estando sempre presente nos segmentos um, sete e oito. Frustulia sp.2 apareceu em 16, sendo em maior número na primavera (5) e verão (6) e em menor no outono (2) e no inverno (3). Frustulia undosa foi encontrada em dez, sendo três na primavera e no inverno e em dois no verão e no outono, sempre mais a montante (segmentos 1 e 5); esteve sempre ausente nos segmentos de rio 3, 6, 7 e 8 , distantes das nascentes. A presença de $F$. weinholdii (nove segmentos) foi maior no período de primavera (5) e de verão (4) e menor no outono (3) e no inverno (2); esteve sempre presente no segmento sete e ausente nos quatro e seis. Amphipleura lindheimeri e Frustulia sp.1 apareceram em oito segmentos cada. A primeira em dois por estação do ano e nos locais mais a montante (segmentos sete e oito). A segunda em quatro segmentos na primavera, um no verão e no outono e em dois no inverno.

As espécies que estiveram presentes em menor número de segmentos foram F. pumilio e Frustulia sp.3, a primeira em quatro, sendo dois na primavera e estando ausente no inverno, e a segunda em um, na primavera. 

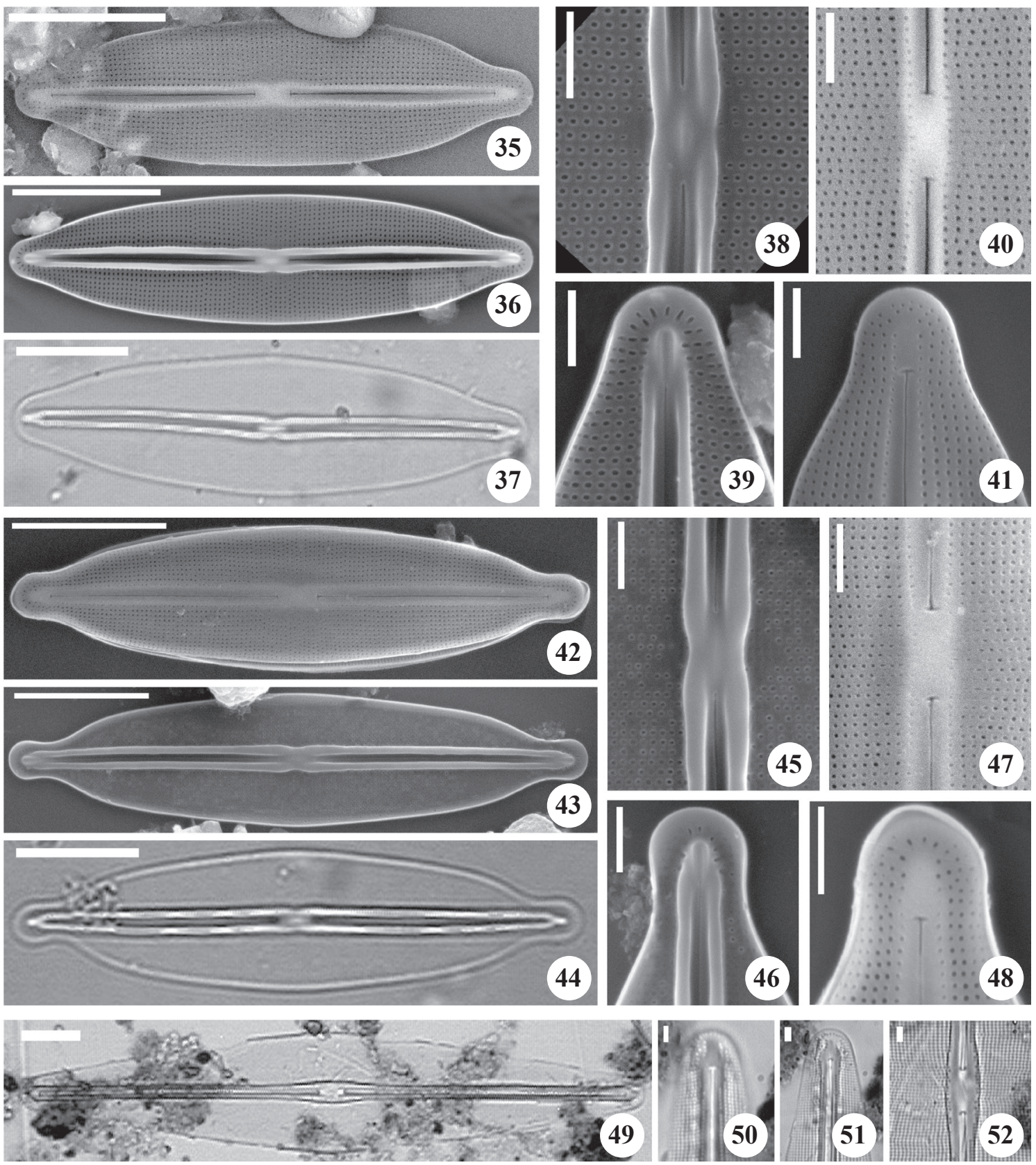

Figuras 35-52. 35-41. Frustulia sp.1. 35. Vista valvar externa (MEV). 36. Vista valvar interna (MEV). 37. Vista valvar (MO). 38. Vista interna da área central (MEV). 39. Vista interna da extremidade valvar (MEV) com a helictoglossa. 40. Vista externa da área central (MEV). 41. Vista externa do ápice valvar (MEV). 42-48. Frustulia sp.2. 42. Vista valvar externa (MEV). 43. Vista valvar interna (MEV). 44. Vista valvar (MO). 45. Vista interna (MEV) da área central da valva. 46. Vista interna da extremidade valvar (MEV) com a helictoglossa. 47. Vista externa da área central (MEV). 48. Vista externa do ápice valvar (MEV). 49-52. Frustulia sp.3. 49. Vista valvar (MO). 50. Extremidade valvar (MO). 51. Extremidade valvar, com foco melhor nas estrias (MO). 52 Área valvar central (MO). Barra $=10 \mu \mathrm{m}(35,36,37,42,43,44,49), 1 \mu \mathrm{m}(38,39,40,41,45,46,47,48), 5 \mu \mathrm{m}(50,51,52)$.

Figures 35-52. 35-41. Frustulia sp.1. 35. External valvar view (SEM). 36. Internal valvar view (SEM). 37. Valvar view (OM). 38. Internal view of central area (SEM). 39. Internal view of valvar end (SEM) with the helictoglossae. 40. External view of central area (SEM). 41. External view of valvar end (SEM). 42-48. Frustulia sp.2. 42. External valvar view (SEM). 43. Internal valvar view (SEM). 44. Valvar view (OM). 45. Valvar internal view of central area (SEM). 46. External view of valvar end (SEM) with the helictoglossae. 47. External view of central area (SEM). 48. External view of valvar end (SEM). 49-52. Frustulia sp.3. 49. Valvar view (OM). 50. Valvar end (OM). 51. Valvar end with striae better focus (OM). 52. Central valvar area $(\mathrm{OM}) . \mathrm{Bar}=10 \mu \mathrm{m}(35,36,37,42,43,44,49), 1 \mu \mathrm{m}(38,39,40,41,45,46,47,48), 5 \mu \mathrm{m}(50,51,52)$. 


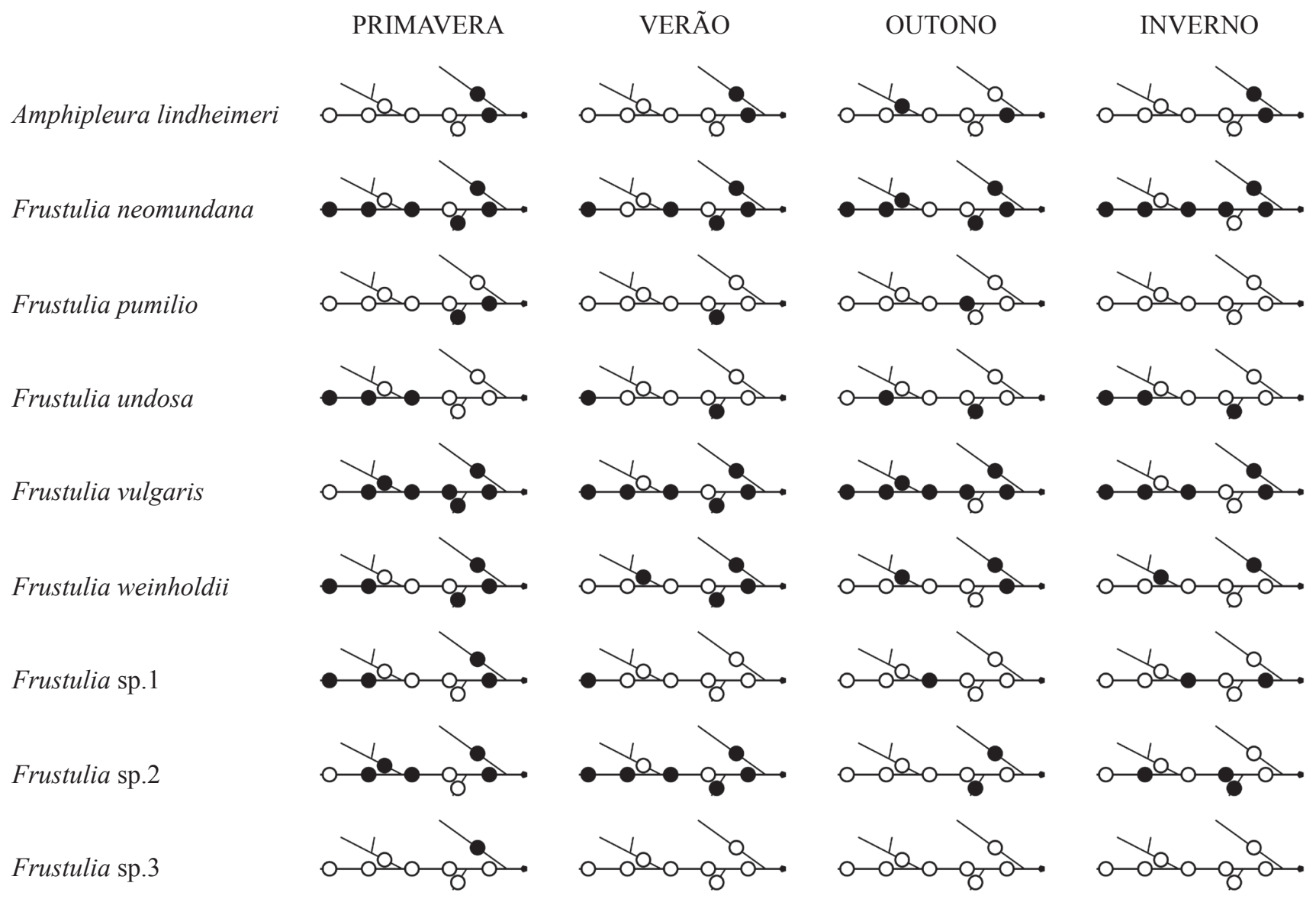

Figura 53. Diagrama representando os rios, a posição dos segmentos de coleta e a respectiva ocorrência das espécies. $(\bullet=$ presente; $O=$ ausente $)$.

Figure 53. Diagram representing the rivers, the position of samples in the segments, and the respective species occurrence. $(\bullet=$ present; $\mathrm{O}=$ absent $)$.

Agradecimentos - Nossos agradecimentos ao Dr. Horst Lange-Bertalot do Instituto de Botânica da Universidade J.W. Goethe, Frankfurt, Alemanha, por sua ajuda e opinião na identificação das espécies e ao Sr. Osvaldo Capello, do Laboratório de Microscopia Eletrônica da Universidade Estadual de Lodrina pelo auxílio nos trabalhos desenvolvidos no MEV. Também agradecemos ao convênio UEL/Confepar/ Fauel pelo suporte econômico dado ao projeto.

\section{Referências bibliográficas}

BRASSAC, N.M. \& LUDWIG, T.A. 2005. Amphipleuraceae (Bacillariophyceae) da bacia do rio Iguaçu, PR, Brasil. Acta Botanica Brasilica 19:359-368.

CAMARGO, M.M. \& MARTINEZ, C.B. 2006. Biochemical and physiological biomarkers in Prochilodus lineatus submitted to in situ tests in an urban stream in southern Brazil. Environmental Toxicology and Pharmacology 21:61-69.
COSTA, J.C. 1995. Diatomáceas (Bacillariophyceae) da Reserva Biológica de Poço das Antas, município de Silva Jardim, Rio de Janeiro, Brasil. Iheringia, Série Botânica, Porto Alegre 46:57-143.

COX, E.J. 1999. Variation in patterns of valve morphogenesis between representatives of six biraphid diatom genera (Bacillariophyceae). Journal of Phycology 35:12971312.

DELL'UOMO,A. 2004. L'indice diatomico di eutrofizzazione/ polluzione(EPI-D) nel monitoraggio delle acque correntiLinee guida. Agenzia per la Protezione dell'Ambiente e per i Servizi Tecnici, Roma, Firenze.

GÓMEZ, N. \& LICURSI, M. 2003. Abnormal forms in Pinnularia gibba (Bacillariophyceae) in a polluted lowland stream from Argentina. Nova Hedwigia 77:389398.

KRAMMER, K. \& LANGE-BERTALOT, H. 1999. Bacillariophyceae, Teil 1. Naviculaceae, Spektrum Akademischer Verlag GmbH, Heidelberg, Berlin. 
KRAMMER, K. \& LANGE-BERTALOT, H. 2000. Bacillariophyceae, Part 5: English and French Translation of the keys, Spektrum Akademischer Verlag GmbH, Heidelberg, Berlin.

LANGE-BERTALOT, H. \& JAHN, R. 2000. On the identity of Navicula (Frustulia) rhomboides and Frustulia saxonica. Systematics and Geography of Plants 70:255261.

LANGE-BERTALOT, H. \& STERRENBURG, F.A. 2004. New Frustulia species (Bacillariophyceae) from fossil freshwater deposits in Florida, U.S.A. Nova Hedwigia 78:527-537.

METZELTIN, D. \& LANGE-BERTALOT, H. 1998. Tropische Diatomeen in Südamerika I. Iconographia Diatomologica. v.5. Koeltz Scientific Books, Königstein.

METZELTIN, D. \& LANGE-BERTALOT, H. 2007. Tropical diatoms of South America II. Iconographia Diatomologia. v.18. Koeltz Scientific Books, Königstein.

METZELTIN, D., LANGE-BERTALOT, H. \& GARCÍARODRÍGUEZ, F. 2005. Diatoms of Uruguay. Iconographia Diatomologica. v.15. Koeltz Scientific Books, Königstein.

MOREIRA-FILHO, H., CECY, I.T. \& VALENTE, I.M. 1976. Diatomáceas da Lagoa Dourada, Estado do Paraná, Brasil. Tribuna Farmacêutica 44:1-14.

MORIN, S., COSTE, M. \& HAMILTON, P.B. 2008a. Scanning electron microscopy observations of deformities in small pennate diatoms exposed to high cadmium concentrations. Journal of Phycology 44:15121518.

MORIN, S., DUONG, T.T. \& HERLORY, O. 2008b. Cadmium toxicity and bioaccumulation in the freshwarter biofilms. Archives of Environmental Contamination and Toxicology 54:173-186.

MORO, R.S. \& FÜRSTENBERGER, C.B. 1993. Diatomáceas (Bacillariophyceae) da Lagoa Dourada (Parque Estadual de Vila Velha), Paraná, Brasil. Acta Biológica Paranaense 22:15-30.
MOURA, A.N. \& BITTENCOURT-OLIVEIRA, M.C. 2004. Diatoms (Bacillariophyceae) of the Tibagi River, southern Brazil. Algological Studies 112: 73-87.

PATRICK, R. \& REIMER, C.W. 1966. The diatoms of the United States. Monographs of the Academy of Natural Sciences of Philadelphia 1:1-688.

RODRIGUES, L. 1991. Naviculaceae (Bacillariophyceae) nas lagoas do Horto Florestal Dr. Luiz Teixeira Mendes, Município de Maringá, Paraná, Brasil. Revista Unimar 13:259-272.

ROUND, F.E., CRAWFORD, R.M. \& MANN, D.G. 1990. The diatoms: biology \& morphology of the genera. Cambridge University Press. Cambridge.

SIVER, P.A. \& BASKETTE, G. 2004. A morphological examination of Frustulia (Bacillariophyceae) from the Ocala National Forest, Florida, USA. Canadian Journal of Botany 82:829-644.

STEVENSON, R.J. \& PAN, Y. 1999. Assessing environmental conditions in rivers and streams with diatoms. In: The Diatoms: Applications for the environmental and earth sciences (E.F. Stoermer \& J.P. Smol, eds.). Cambridge University Press, Cambridge, p.11-40.

TORRISI, M. \& DELL'UOMO, A. 2001. Les diatomées benthiques des parties rhithrales et potamales des cours d'eau de l'Apennin central (Italie) et leurs significations écologiques. Algological Studies 102:35-47.

WINKALER, E.U., SILVA, A.G., GALINDO, H.C. \& MARTINEZ, C.B. 2001. Biomarcadores histológicos e fisiológicos para o monitoramento da saúde de peixes de ribeirões de Londrina, Estado do Paraná. Acta Scientiarum 23:507-514.

WOJTAL, A. 2003. Diatoms of the families Amphipleuraceae and Brachysiraceae from the Wyzyna KrakowskoCzestochowska upland (S Poland). Polish Botanical Journal 48:55-61.

YABE, M.J. \& OLIVEIRA, E. 1998. Metais pesados em águas superficiais como estratégia de caracterização de bacias hidrográficas. Química Nova 21:551-556. 